\title{
How Do Innovation Network Structures Affect Knowledge Sharing? A Simulation Analysis of Complex Networks
}

\author{
Lupeng Zhang and Wenbo Chen (iD \\ School of Public Administration, Beihang University, Beijing, China \\ Correspondence should be addressed to Wenbo Chen; wenbo.chen@buaa.edu.cn
}

Received 30 July 2020; Revised 17 December 2020; Accepted 22 December 2020; Published 5 January 2021

Academic Editor: Yi Su

Copyright (c) 2021 Lupeng Zhang and Wenbo Chen. This is an open access article distributed under the Creative Commons Attribution License, which permits unrestricted use, distribution, and reproduction in any medium, provided the original work is properly cited.

\begin{abstract}
Knowledge has become an important resource that can help enterprises gain a competitive advantage in the market. In this regard, knowledge sharing in the process of cooperative innovation provides an important way to acquire knowledge. With the development of innovation, the innovation network has become an important carrier of knowledge sharing, which can also have an influence on knowledge sharing. Based on knowledge management theory and complex network theory, this study constructed a multilayer network environment for knowledge sharing. It then identified the network elements and knowledge-sharing paths that influence knowledge sharing from microperspectives and macroperspectives. On this basis, the effects of node cohesion and weak connection on knowledge sharing in small-world and scale-free topologies were analyzed by computer simulation. The results showed that, in an innovation network with a scale-free topology, cohesion and weak ties had a great influence on the average knowledge level and knowledge equilibrium. Meanwhile, in small-world topological innovation networks, a mixed path had the best promotion effect on network knowledge sharing.
\end{abstract}

\section{Introduction}

Under the ongoing "Fourth Industrial Revolution," emerging industries tend to be more knowledge intensive and less focused on the consumption of material resources [1]. The rapid development of such industries can directly affect regional and national development levels and enhance competitiveness. Specifically, emerging industries based on scientific knowledge can help developing countries catch up with technology and promote their future development [2]. Knowledge, therefore, has become a high-value asset for achieving innovation and creating wealth. The knowledge and technology that promote enterprise development require learning, sharing, and diffusion. Thus, in the era of the knowledge economy, knowledge is an important factor for economic growth; knowledge sharing's contribution to economic growth is even considered greater than that of knowledge innovation itself [3].
With the accelerated development of science and technology, cross-field knowledge is becoming increasingly integrated into emerging industries. The increasing demand for rapid, high-quality innovation creates challenges for enterprises' technological innovation. In this regard, individual innovation activities can have difficulty adapting to a changing innovation environment [4]. With the goal of sharing benefits and risks, enterprises, universities, and institutions form alliances to jointly overcome such difficulties. These innovation networks formed by industryuniversity-research cooperation have given rise to a new organizational form that is becoming increasingly systematic and complex [5]. Accordingly, the influence of the network structure on knowledge sharing has become an important research topic.

Knowledge sharing is a behavior that allows different types of knowledge to be shared between different subjects, resulting in new knowledge. The knowledge- 
sharing process has been studied from three perspectives. First, transaction theory suggests that knowledge is scarce and can be sold in an alliance to gain profits [6]. Therefore, obtaining profits through such an exchange of knowledge is a knowledge-sharing process. Second, knowledge transfer theory suggests that knowledge sharing is a process in which subjects possessing knowledge transfer that knowledge to subjects who want to use knowledge more efficiently. New knowledge is generated in this process of knowledge transfer $[7,8]$. Third, according to organizational learning theory, knowledge sharing is a process in which enterprises communicate with each other and receive the knowledge they need. Through this process, enterprises promote and share their knowledge with other enterprises in the alliance and encourage member firms to continue learning to achieve knowledge sharing [9]. In this knowledge-sharing process, information technology development levels [10], organizational incentives [11], and organizational environments [12] affect knowledgesharing efficiency. Alliance networks have become an important channel for enterprises to acquire, integrate, and utilize external knowledge resources. Knowledge networks [13], structural diversity [14], and network structures will affect the efficiency of knowledge sharing $[15,16]$. Cowan found that "small-world" networks were the most conducive to knowledge sharing and diffusion, and the shorter the average network path, the more rapid and complete the knowledge-propagation process [17]. However, too much similarity in a community structure can hinder knowledge sharing [18]. Lin found that knowledge sharing performed best in scale-free networks [19]. Su and Li constructed a knowledge-transfer model for a knowledge alliance based on acoustic-wave theory and found positive correlations among the number of enterprises in a knowledge alliance, knowledge-transfer frequency, and knowledge-transfer effect [20]. Two gaps can be identified in the literature. First, most existing studies constructed a network environment for knowledge sharing and analyzed its influence from a macroperspective while ignoring the influence of strong and weak ties on knowledge sharing between microindividuals. Second, the knowledge in the organization exists in the form of knowledge network. Thus, a traditional single-layer network model cannot describe the knowledge network owned by an actual organization in a detailed and comprehensive way.

The present study, therefore, utilized multinetworks to describe the carrier of knowledge sharing and explain its process. Moreover, complex network theory was adopted to deal with the structural characteristics of innovation networks. On this basis, this study constructed a mechanism model and analyzed how network structures influence knowledge sharing in multinetworks. We focused on two questions: Q1: which network elements affect knowledge sharing from macroperspectives and microperspectives? Q2: how do these elements affect knowledge sharing in multinetworks? This study focused, therefore, on the process of knowledge sharing among different organizations and examined the influence of network elements on knowledge sharing. Accordingly, this study's findings have implications for governments, researchers, and industries.

The rest of this paper is organized as follows: Section 2 reviews the literature, which forms the basis for the analytical framework. Section 3 analyzes the knowledge-sharing model in the innovation network that was established to explain the mechanism of knowledge sharing. Then, in Section 4, numerical simulation is used to construct the related mechanisms that can promote knowledge sharing in innovation networks. Section 5 provides conclusions and suggestions.

\section{Literature Review}

2.1. Knowledge Sharing. Knowledge has public goods, transfer, and agglomeration characteristics, which allow innovation subjects to smoothly transfer knowledge through cooperation and thereby obtain benefits. Polanyi and Nonaka proposed the classic division of knowledge. According to whether knowledge can be expressed and how much it can be expressed, they divided knowledge into explicit and implicit knowledge [21, 22]. Explicit knowledge is the knowledge that is clearly expressed, usually in a publicly accessible manner, such as written text, numbers, or graphics. Explicit knowledge can be effectively transmitted through media and can be received by most groups. Implicit knowledge, meanwhile, has a low degree of explicitness. It is difficult to express implicit knowledge through precise language; it can only be accessed through communication and learning between individuals [23]. Therefore, cooperation provides a good platform for the transfer of implicit knowledge. During the cooperation process, collaboration parties can learn, grasp, and transmit implicit knowledge that cannot be easily expressed through words [24].

Knowledge sharing is a process of knowledge transmission between individuals and organizations; it represents the organic unity of knowledge transfer and knowledgeabsorption processes [25], as well as the acquisition, integration, and creation of knowledge and information [26]. Knowledge sharing is thus the core of knowledge production and plays an important role in knowledge inheritance and knowledge innovation [27]. Knowledge sharing enables innovative organizations to create knowledge by learning from other organizations. Efficient knowledge sharing helps implicit knowledge become more explicit and facilitates knowledge innovation through knowledge externalization, internalization, integration, and absorption [28]. Knowledge sharing, moreover, facilitates communication among members of an organization, which in turn helps innovation subjects acquire required knowledge, narrows the knowledge gap between parties, and accelerates innovation diffusion [29]. Knowledge sharing also has positive externalities 
[30]. Through knowledge sharing, both parties gain knowledge from each other, pursue knowledge innovation, spread knowledge to the organizational level of the innovation network, improve knowledge exchange, and support technological innovation [31]. Therefore, knowledge sharing is a dynamic process in which knowledge acquirers contribute to the value of an organization. It is only through such means that knowledge can be absorbed, utilized, and transformed into an ascending spiral. Managing knowledge in the system can provide a fourfold value through knowledge acquisition and selection, processing and absorption, sharing and transfer, and innovation and creation. Under specific network conditions, the mechanism of knowledge flow within an organization forms a knowledgesharing process, which ensures knowledge sharing and organizational identity among organization members with compatible knowledge structures and cultural backgrounds [32].

Based on the literature, this study defines knowledge sharing as the process of knowledge dissemination and recreation, that is, the whole process of knowledge recreation through direct or indirect communication and interaction between subjects (subject can also be a node in a network) in an innovation network, absorbing each other's knowledge advantages in the presence of differences in knowledge potential.

\subsection{Innovation Networks and Complex Networks. An in-} novation network is an open and dynamic complex system [33]. It is a basic institutional system that serves the systemic innovation of the subjects. The innovative cooperation relationship between enterprises is the main bridging mechanism of the network frame [34]. This relationship is mostly maintained by contracts. The content of the relationship is the innovation activities between the innovation subjects, and the ultimate goal is to maximize the benefits of all participants. Under the influences of technology spillover [35], knowledge integration [36], innovation dependence [37], organization proximity [5], and other factors, nodes in the network constantly adjust strategies according to development needs in the process of activities; original innovation subjects are reintegrated, new subjects are constantly added, and the innovation network structure transitions from looseness to centralization [38]. An innovation network gradually assumes the form of a "smallworld" with strong cohesion [39], evolving from a low level to a high level. It gradually forms an innovative system with the characteristics of open growth, selective connectivity, and complex multisubjectivity [40]. An innovation network contains significant innovative talent. Through collaborative cooperation, talented individuals who possess knowledge can share that information and communicate with different subjects, thus injecting knowledge. Because an innovation network has a large number of complex connected relationships, the inflow of resources, such as innovation knowledge, is broadened, and knowledge is aggregated.
Therefore, the formation of an innovation network provides a platform for knowledge sharing, which in turn promotes the development of an innovation network.

In recent decades, as a kind of complex social network, innovation networks have been increasingly formed to promote innovation and knowledge sharing. Complex networks are applied to explain the formation and evolution of innovation networks [41]. A complex network is a set of graphs composed of nodes and their relationships. The nodes in a complex network are numerous and diverse. Connections between nodes can appear or disappear at any time. The fusion of multiple behaviors leads to high complexity and evolution [42], which are mainly manifested in structural complexity, network evolution, and node diversity. Analyzing the concepts and characteristics of complex networks and innovative networks reveals that the two have similarities in terms of their network attributes, as shown in Table 1.

Since innovation networks are similar to complex networks (i.e., the nodes are diversified, the connections are complex, and there are certain evolutionary characteristics), studies generally use the measurement indexes of complex networks to measure innovation networks [44].

In summary, this study defines an innovation network as the interrelated organizational structure formed by innovation subjects in the process of cooperation and communication, and it is measured using the related indexes of complex networks.

\subsection{Network Structure and Its Effect on Knowledge Sharing.} Knowledge sharing is a process of knowledge transfer and recreation between innovation subjects. To fill knowledge gaps, innovation subjects in a network must cooperate with other subjects to promote knowledge sharing and integrate knowledge. Only by realizing knowledge sharing can innovation subjects achieve technological innovation and improve their innovation performance. Therefore, the present analysis of knowledge sharing in innovation networks is designed to explore the knowledge transfer and creation process in an innovation network, thus helping innovators identify a better knowledge-sharing pattern. The knowledge-sharing process includes knowledge transfer and knowledge creation. Knowledge transfer emphasizes the process of knowledge transfer from provider to recipient. The knowledge provider has an absolute knowledge advantage, and the knowledge receiver, based on the subjects' innovation needs, can acquire, absorb, and utilize complementary knowledge through cooperation and exchange. Knowledge creation emphasizes the socialization and internalization of implicit knowledge, highlighting the ascending-spiral process of knowledge.

The cooperation and communication relationship between subjects in an innovation network is the link that helps them acquire and utilize complementary and heterogeneous knowledge. Innovation subjects can access cutting-edge knowledge in the process of communication and 
TABLE 1: Attribute comparison between complex networks and innovation networks.

\begin{tabular}{|c|c|}
\hline $\begin{array}{l}\text { Main properties of complex networks } \\
\text { [43] }\end{array}$ & Main properties of innovation networks [41] \\
\hline $\begin{array}{l}\text { The number and types of network } \\
\text { nodes are varied. }\end{array}$ & $\begin{array}{r}\text { The number of innovation nodes is in } \\
\text { universit }\end{array}$ \\
\hline $\begin{array}{l}\text { The structure of the network is } \\
\text { complex. }\end{array}$ & $\begin{array}{c}\text { There is a great deal of nonlinear positive and negative feedback between innovation subjects, } \\
\text { which makes the innovation network a complex system with complex structures, intricate } \\
\text { relationships, and diverse target functions. }\end{array}$ \\
\hline $\begin{array}{l}\text { It involves the dynamic evolution } \\
\text { time and space. }\end{array}$ & $\begin{array}{l}\text { They have complex evolution characteristics. The innovation subject carries on the } \\
\text { transformation connection according to resource endowment preference differences. Meanwhile, } \\
\text { external nodes are attracted to join the network, causing the relationships between innovation } \\
\text { subjects to change constantly, and the network evolves accordingly. }\end{array}$ \\
\hline
\end{tabular}

cooperation. Meanwhile, the knowledge-communication relationship established with heterogeneous subjects can help enterprises build their reputation in the network and help them form more network relations to acquire rich external knowledge [45]. Due to differences in the frequency, intensity, and number of connections between the subjects, a diversified network structure is formed, and the structural position of the subject is an important basis for measuring the knowledge capital it can obtain. With principals at the center of the network, they will have more opportunities to use and control information and resources [46]. A network with more structural holes can facilitate knowledge diffusion by promoting the adoption of nonredundant information and knowledge, carrying out middleman business, and acquiring tangible resources [47]. The popularity and activity of individuals in the network are often considered the key area regarding the function of the "structure diagram" or "bridge connection." Therefore, subjects occupying structural holes and having more bridge connections can obtain more heterogeneity and advantageous information [48]. In addition, some stable network structure relationships will be formed among individuals who have established connections, which is conducive to the acquisition and sharing of knowledge [49].

In summary, the network structure formed by an innovation network and the network locations of the innovation subject both influences the subject's knowledge acquisition. This study examined knowledge sharing in an innovation network from two aspects: microindividual network elements and macronetwork topologies. From the microperspective, subjects with direct connections can share knowledge through direct cooperation, exchange, and recreation. Therefore, the cohesion of nodes has an effect on knowledge sharing; the more subjects with direct connections, the higher the cohesion. In addition, the positive externality of knowledge sharing enables subjects without direct connections to acquire knowledge through indirect relations, such as "structural holes" and "bridge connections"; thus, the weak ties of nodes will also have effects on knowledge sharing. From the macropoint of view, different network topologies determine the sharing efficiency and knowledge paths in the network. Therefore, this study established knowledge-sharing paths, including direct, indirect, and mixed paths. A direct path reflects the influence of node cohesion on knowledge sharing, while an indirect path reflects the influence of weak ties among knowledgesharing nodes.

\section{Method}

3.1. Multinetwork Model. Based on the literature review, to describe the knowledge-sharing process in innovation networks, this study constructed a knowledge network based on knowledge elements and an innovation network for knowledge sharing. It then simulated the relationship between the two networks to build a multilayer network of knowledge sharing.

3.1.1. Construction of a Knowledge Network. The basic components of a knowledge network include related knowledge in the network organization. Drawing on previous studies [50], we described the knowledge possessed by individuals in an innovation network by creating a knowledge-network tree diagram. We divided the knowledge used by an organization into a knowledge field and a knowledge unit (KU), as shown in Figure 1. In this paper, we defined the knowledge field as some kinds of knowledge in different industries or in different subjects; it can be divided into different knowledge unit. And knowledge unit refers to the knowledge with a complete expression that cannot be divided. The knowledge stock of the network node was represented at the same level, and the knowledge source at the same level did not have overlapping knowledge. Knowledge networks are represented by innovation networks, where $K$ means nodes in the network and $V$ means relationship in the network. Thus, we have $V_{k}=\left\{\left(k_{i}, k_{j}\right) \mid \theta\left(k_{i}, k_{j}\right)\right\}$. If $\theta=1, K_{i}$ is the subnode of $K_{j}$; otherwise, there is no connection relationship between $K_{i}$ and $K_{j}$. 


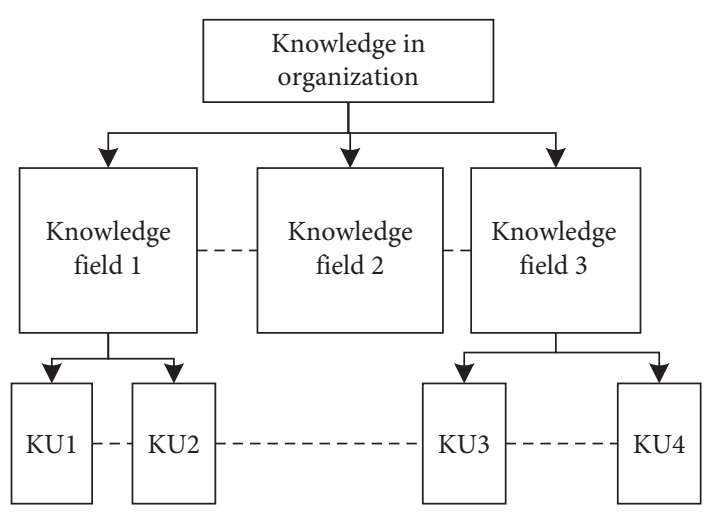

Figure 1: Diagram of a knowledge network.

3.1.2. Construction of an Innovation Network. "Innovation network" describes the relationship between each innovation subject. This study used the complex-network metaphor for the innovation-network environment. Small-world and scale-free networks are common complex networks. The small-world network is a common complex network proposed by Watts and Strogatz. The node degree of a small-world network presents Poisson distribution characteristics. This network has a high clustering coefficient and a short average path length [51]. Complex networks with a scale-free structure exhibit the following two characteristics: first, the number of nodes is constantly increasing; second, newly added nodes and original nodes are connected based on the principle of "degree preference" (higher-degree nodes are selected more often) [52]. We constructed innovative cooperation networks with these characteristics. The cooperation network expression is $\mathrm{NC}=\left(K_{c}, V_{c}\right)$, where $K_{c}$ is the number of subjects in the cooperation network, and $V_{c}$ is the connection relationship in the cooperation network. If $V_{c}=1$, a cooperative relationship exists between the innovation nodes; if $V_{c}=0$, no connection relationship exists between the innovation nodes.

In general, studies have used network average degree and average path length to describe the topology structures of complex networks. The degree of nodes refers to the number of edges that other nodes in a complex network are directly connected via a specified node, called $k_{i}$. Degree is an index for measuring the relationship between nodes in a network. The average degree of all nodes in the network becomes the average degree of the network.

Average path-length $L$ refers to the shortest path between nodes $i$ and $j$ in a network as follows:

$$
L=\frac{1}{(1 / 2) N(N-1)} \sum_{i \geq j} d_{i j},
$$

where $N$ represents the number of nodes in the network and $d_{i j}$ is the geodesic distance between two nodes. The smaller the average path length, the shorter the distance between nodes; that is, the shorter the time needed to reach the target position, the less the authenticity.

3.1.3. Multilayer Network Construction. Network members in a cooperative innovation network possess relevant knowledge in the knowledge network. Therefore, the relationship between the innovation network and the knowledge network was constructed, and the relationship formed among networks constitutes a knowledge-sharing multilayer network in the innovation network (Figure 2). This study established an array $v[n, m]$ to express the amount of knowledge owned by members of the innovation network.

3.2. Mechanism of Knowledge Sharing in Multinetworks. Innovation subjects at this stage of socialization utilize mobile resources and communicate with innovation subjects in the network to acquire implicit knowledge. The innovation network provides a communication exchange platform for innovation subjects to conduct social activities. Innovation subjects make the acquired implicit knowledge more explicit to renovate and transform the implicit knowledge of the individual into the public knowledge of the network [28]. Innovation subjects then integrate scattered knowledge into the network through a joint process and integrate the implicit knowledge acquired in the first and second stages, forming a knowledge-innovation system. In the process of internalization, innovation subjects absorb knowledge, create new knowledge through practice and learning, and continue the process of knowledge transfer, knowledge processing, knowledge integration, and knowledge innovation [53]. In addition, innovation subjects absorb useful knowledge, process knowledge based on its advantages, transfer new knowledge to the innovation system, and achieve the two-way circulation of knowledge through transferring and sharing. We can conclude, therefore, that innovation ability, learning ability, and degree of explicitness affect 


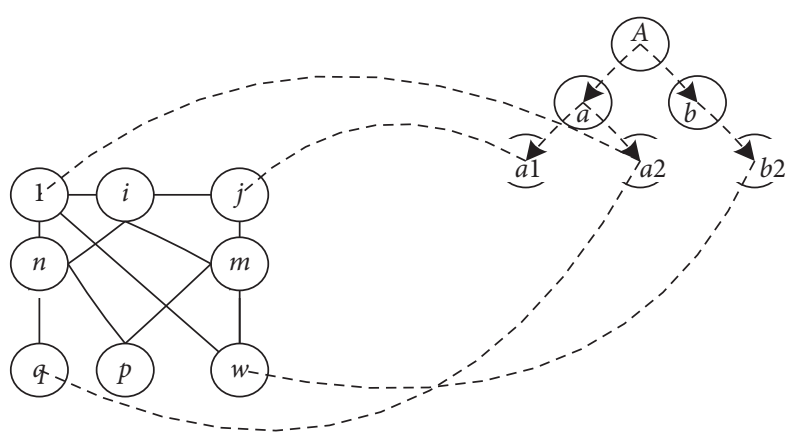

FIGURE 2: Multilayer knowledge network diagram.

the efficiency of knowledge sharing in a network. Knowledge is transferred, absorbed, digested, shared, and recreated among cooperative innovation organizations, achieving an ascending-spiral process of communication, coordination, cooperation, and collaboration [54].

This study focused on the process of knowledge sharing between organizations. A multilayer network structure was used to describe the carrier of knowledge sharing. Based on the analysis in Section 2.3, this study divided the knowledgesharing path in the innovation network into three types: direct path, indirect path, and mixed path.

Direct path (DP) refers to knowledge sharing in the knowledge network via direct contact between subjects in the innovation network. Such direct contact and learning usually promote the transmission of tacit knowledge in the network. When innovation subjects in the innovation network cooperate, they communicate with each other and share knowledge with the knowledge-learning party. Since tacit knowledge is stored in the mind of the knowledge provider, it cannot be encoded with specific words; meanwhile, the knowledge receiver can acquire knowledge through the establishment of a connection relationship to enhance their own knowledge reserve and complete the process of knowledge transfer.

Under DP, it is assumed that the knowledge provider $\left(P_{a}\right)$ has a certain kind of knowledge $\left(K_{i j}\right)$. After a round of knowledge sharing, the new knowledge possessed by the knowledge-learning party is only affected by its own cohesion - that is, the influence of the subject in direct contact with it. If there is a knowledge gap between the two nodes, $P_{a}$ will own some knowledge units of the other node, and the greater the degree of $k$, the more knowledge it will likely share. Since knowledge potential decreases with increased communication between two parties, the knowledge potential attenuation function $F(\alpha)$ is introduced. $F(\alpha)$ is a power function varying with time, and $k$ is the degree of the node. After a round of knowledge diffusion and learning, the efficiency of knowledge sharing is

$$
D_{a}(t+1)=I_{a}(t)+F(\alpha) * k .
$$

Under the indirect path (IP), it is assumed that the knowledge provider $\left(P_{a}\right)$ has a certain kind of knowledge $\left(K_{i j}\right)$. The efficiency of knowledge sharing is only affected by the indirectly connected subject-that is, the number of weak ties. In this study, the average path length $L$ of the innovation network was chosen to represent the weak ties of nodes. After a round of knowledge diffusion and learning, the efficiency of knowledge sharing is

$$
I_{a}(t+1)=I_{a}(t)+F(\alpha) \hat{L} .
$$

Under the mixed path (MP), the knowledge owner will select the DP according to equation (2) at probability $P$, and the knowledge owner will select the IP according to equation (3) at probability $1-P$ :

$$
M_{a}(t+1)=p D_{a}(t+1)+(11 p) I_{a}(t+1) .
$$

As shown in Figure 3, the innovation network is composed of 1-7. For example, after a round of knowledge sharing and learning, subject 2 can be shared through a DP to learn the knowledge of subject 1 . Meanwhile, it can also be shared from node 3 and node 8 through the IP.

3.3. Measure of Knowledge Sharing. Assuming the initial knowledge stock $\mathrm{TK}_{\mathrm{PS}}(t)$ of each innovation subject in the innovative network NC is the sum of the initial stock of various types of knowledge owned by the subjects, we have

$$
T K_{P_{a}}(t)=\sum_{k_{i j}=1}^{m} v\left(P_{a}, k_{i j}\right)(t) \text {. }
$$

The total amount of knowledge in the innovation network is 


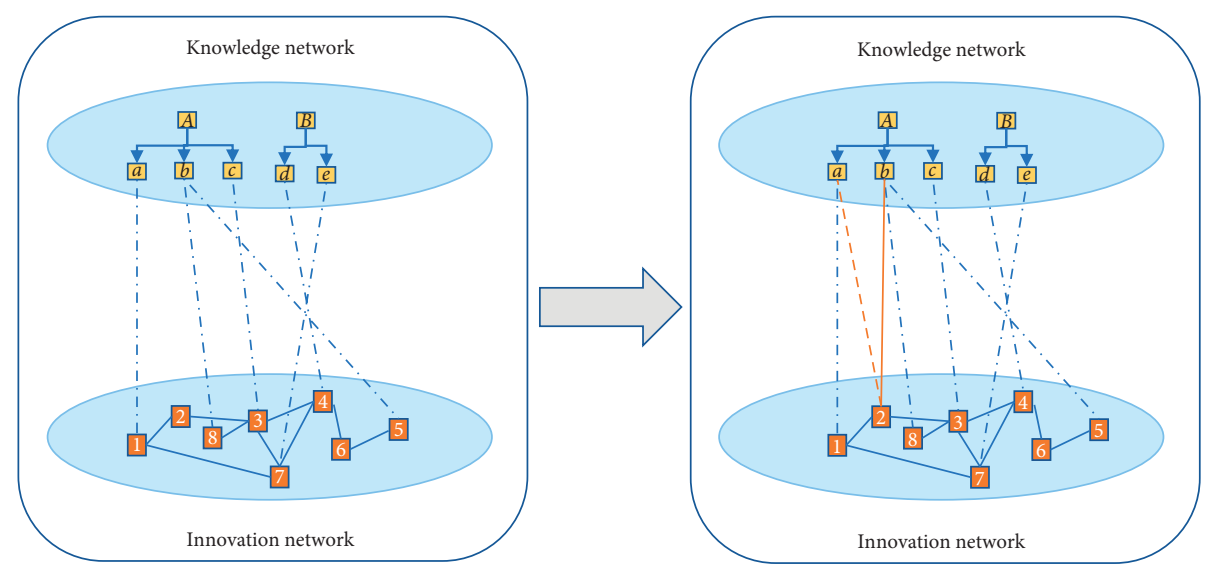

FIGURE 3: Mechanism of knowledge sharing in multilayer networks.

$$
T K_{P_{a}}(t)=\sum_{P_{a}=1}^{n} v\left(P_{a}, k_{i j}\right)(t) .
$$

According to the relationship between the innovation network and the knowledge network, a multilayer network expression, $\mathrm{SN}=\left(K, V, V_{k-k}, V_{c-c}, V_{k-c}\right)$, is established, where $V_{k-c}$ is the set of edges that connects the innovation nodes in the knowledge network and innovation network in the multilayer network. In the simulation, the matrix element value is set to 0 or 1 to indicate whether knowledge field $i$ has knowledge unit $j$. The number of knowledge units in the network is $m$, which is the sum of all nonzero elements in the innovation network.

Efficient knowledge sharing can promote collaboration between innovation subjects and enhance innovation performance. Knowledge sharing is one of the goals of collaborative innovation. The level of knowledge measures the efficiency of knowledge transfer in an innovation network. In a certain period of time, the faster the knowledge level in the innovation network grows, the higher the knowledge-sharing efficiency of the network. Therefore, this study used the knowledge level to measure the knowledge-sharing efficiency of the whole network. In addition, the knowledge balance in an innovation network can measure the level of knowledge development in the overall network. The higher the balance, the stronger the cohesiveness of the network, and the more similar the knowledge acceptance ability of each innovation subject. This study selected the average knowledge level and knowledge equilibrium level to measure the efficiency of knowledge sharing in an innovation network. The equations are as follows:

$$
\begin{aligned}
u(t) & =\frac{1}{n} \sum_{P=1}^{n} \mathrm{TK}_{P}(t), \\
\sigma^{2} & =\frac{1}{n} \sum_{P=1}^{n} \mathrm{TK}_{P}^{2}(t)-u^{2}(t) .
\end{aligned}
$$

\section{Simulation and Discussion}

4.1. Steps and Parameter Initialization Settings. Based on the rules of knowledge sharing in a multilayer network, we designed the following simulation steps:

Step 1. The NC of an innovation network and NK of a knowledge network with a certain number of nodes are constructed. To simulate the influence of different structures on knowledge sharing, innovation networks with small-world characteristics and scale-free characteristics are generated.

Step 2. Small-world and scale-free networks with 500 nodes were generated based on the literature [55]. Set the average degrees of the network as 2, 4, and 8 and the average path lengths of the network as 2,6 , and 8 .

Step 3. When $t=0$, knowledge elements are randomly assigned to nodes in the innovation network, and the initial average knowledge level and knowledge equilibrium of the network are calculated according to equations (7) and (8).

Step 4 . When $t=1$, after the knowledge sharing and learning of all nodes according to equations (2)-(4), the average knowledge level and knowledge equilibrium of the network are calculated according to equations (7) and (8).

Step 5. Repeat steps $2-4$. The simulation is terminated after 10,000 times; it then generates simulation diagrams of the knowledge-sharing effects in different network topologies.

Following the given simulation steps, we used MATLAB R2019b to generate knowledge-sharing effect diagrams in the innovation network with different parameter settings.

4.2. Knowledge Sharing in a Scale-Free Network. Figures 4 and 5 show the effects of node cohesion and the number of weak ties on the average knowledge level and knowledge equilibrium in a multilayer network with a scale-free topology. 

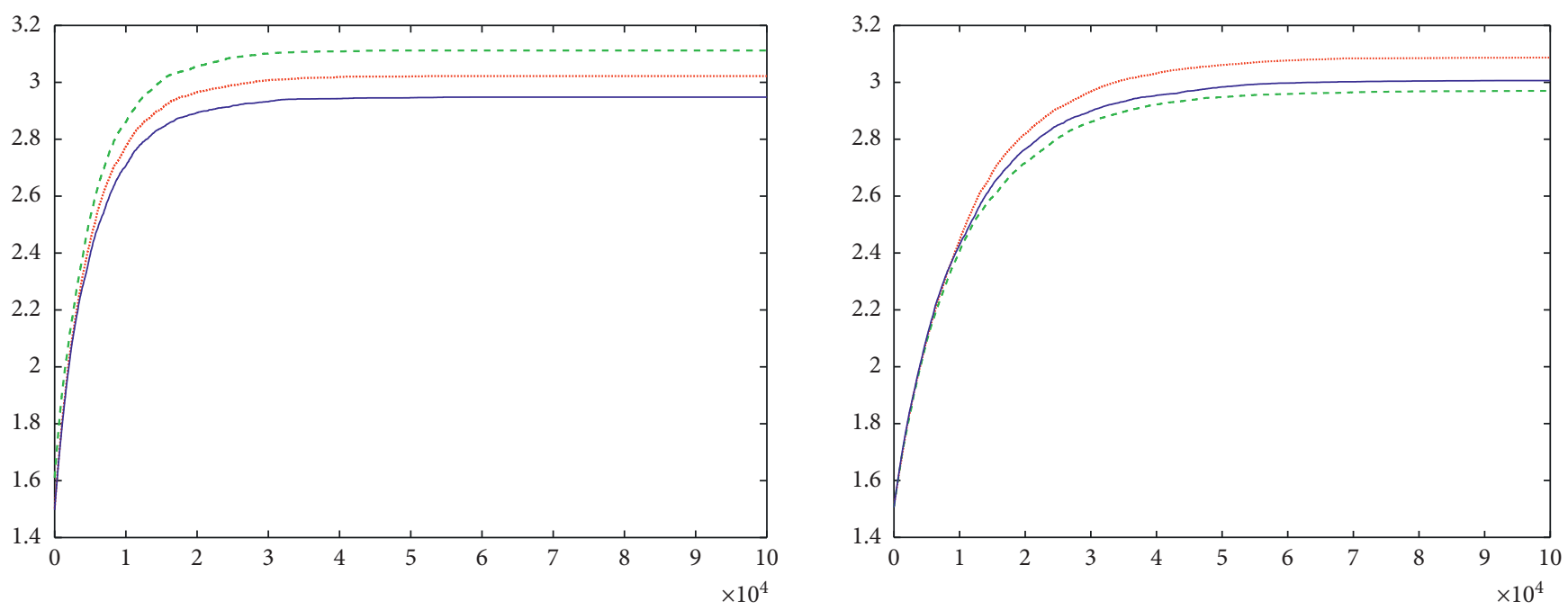

......... DP
$\ldots$ - - IP
- MP

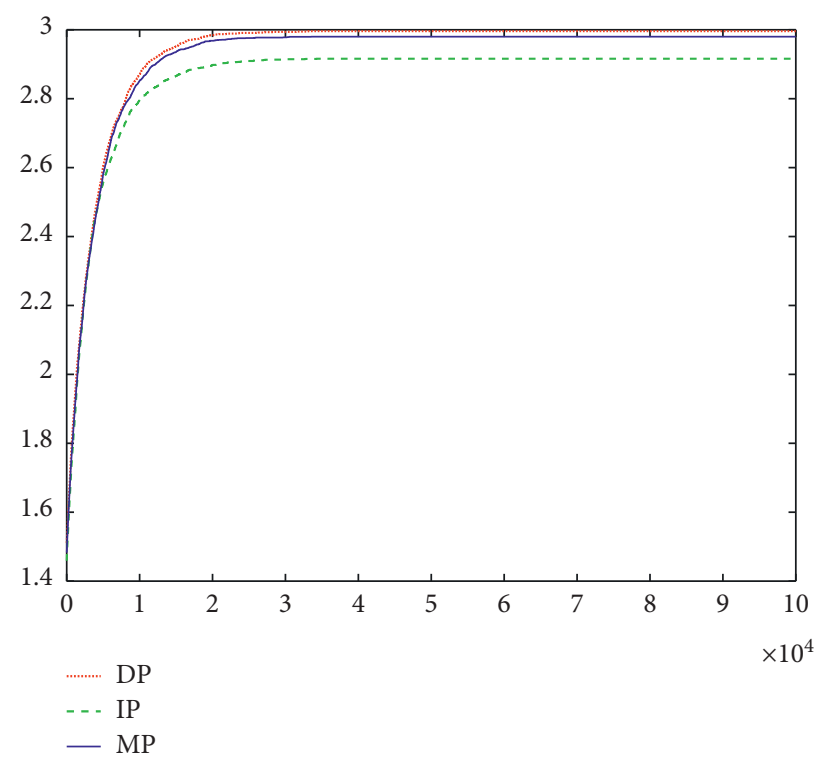

FIGURE 4: Levels of average knowledge in a scale-free network when $k=2$, 4 , and 8 .

When node cohesion $k$ is 2 , 4 , and 8 , the average knowledge level and knowledge equilibrium in the innovation network under a scale-free topology are shown in Figures 4 and 5.

As shown in Figure 3, as node cohesion increased, under a scale-free network environment, the average knowledge level of the innovation network decreased gradually in the DP, MP, and IP. In a scale-free network environment and according to the "Matthew effect" of a scale-free network, as the number of innovation nodes increased, new nodes cooperated with old nodes that had stronger cohesion and more connected relationships. Existing subjects in the network acquired their partners' explicit knowledge through encoded documents and needed more implicit knowledge that could be accessed through cooperation and communication. Therefore, when innovation subjects had stronger cohesion, DP was more conducive to the sharing and creation of network knowledge.

As shown in Figure 5, as node cohesion increased, the innovation network's knowledge equilibrium gradually changed from IP to DP in the scale-free network. Knowledge equilibrium reflected the stock of knowledge owned by each subject in the network. When node cohesion was low, each subject in the IP acquired more similar knowledge through the encoded knowledge. At this time, the network balance was the strongest. As 

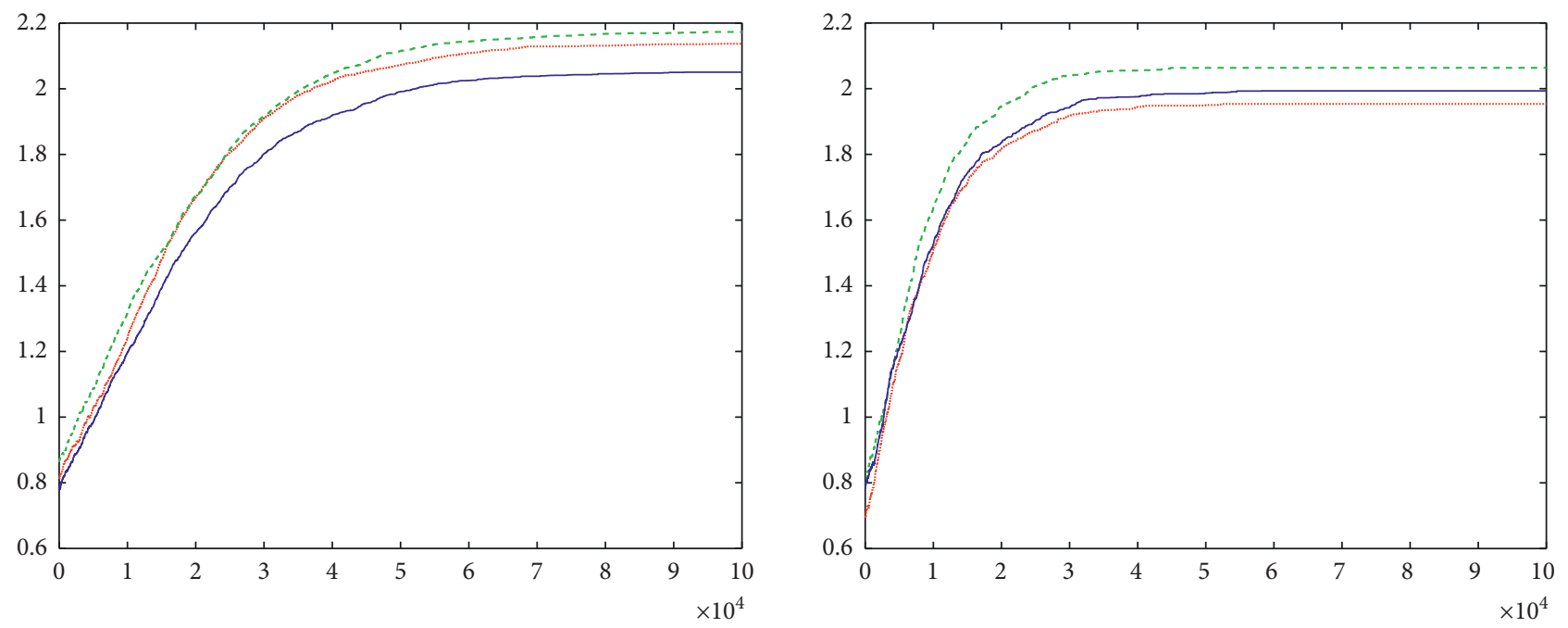

$$
\begin{array}{ll} 
& \mathrm{DP} \\
\ldots & \mathrm{IP} \\
- & \mathrm{MP}
\end{array}
$$$$
\ldots-. . \mathrm{DP}
$$$$
\text { -.. IP }
$$$$
-\mathrm{MP}
$$

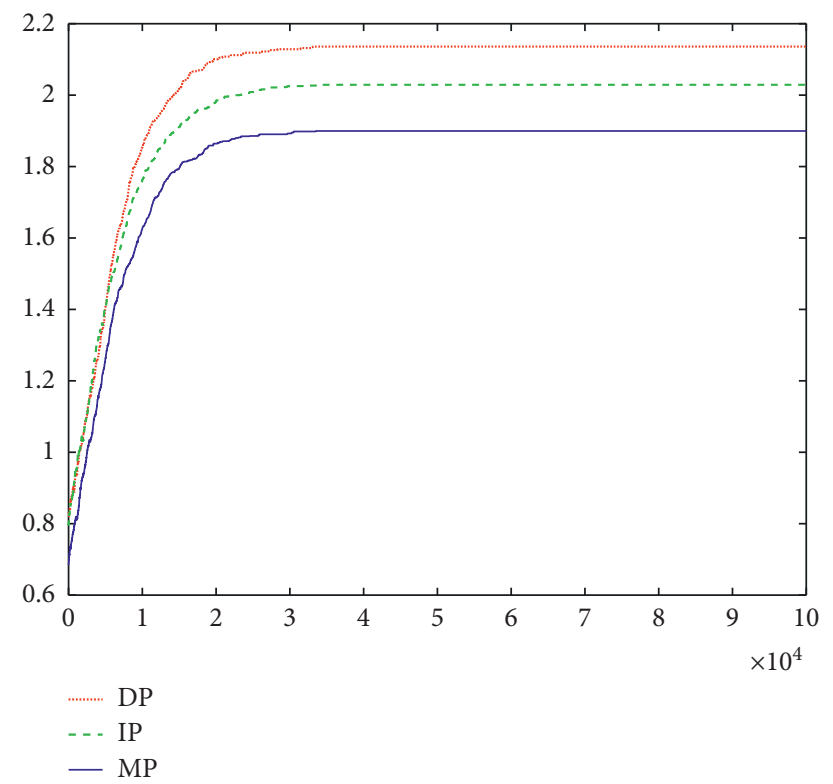

FIgURE 5: Knowledge equilibrium in a scale-free network when $k=2,4$, and 8 .

subject cohesion was enhanced, subjects with a relatively high value in the scale-free network acquired implicit knowledge through direct communication. Under the joint catalysis of implicit and explicit knowledge, the collaboration and equilibrium of subjects under DP were gradually enhanced. Therefore, in the process of collaborative innovation, innovation subjects should constantly self-evaluate, master their innovation ability, select appropriate knowledge-sharing channels according to their ability, and improve collaboration efficiency.

When the learning ability of innovation subjects $L$ is 2, 6, and 8 , the average knowledge level and knowledge equilibrium in the innovation network under a scale-free topology are shown in Figures 6 and 7.

As shown in Figure 6, MP and IP influenced the effect of weak ties on the level of knowledge sharing, whereas MP 


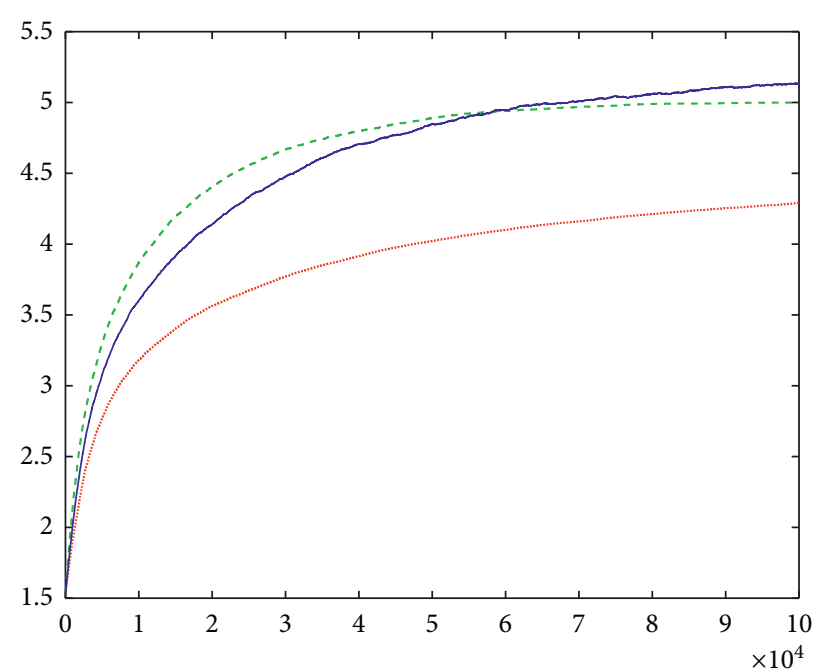

.......... DP

-.. IP

$-\mathrm{MP}$

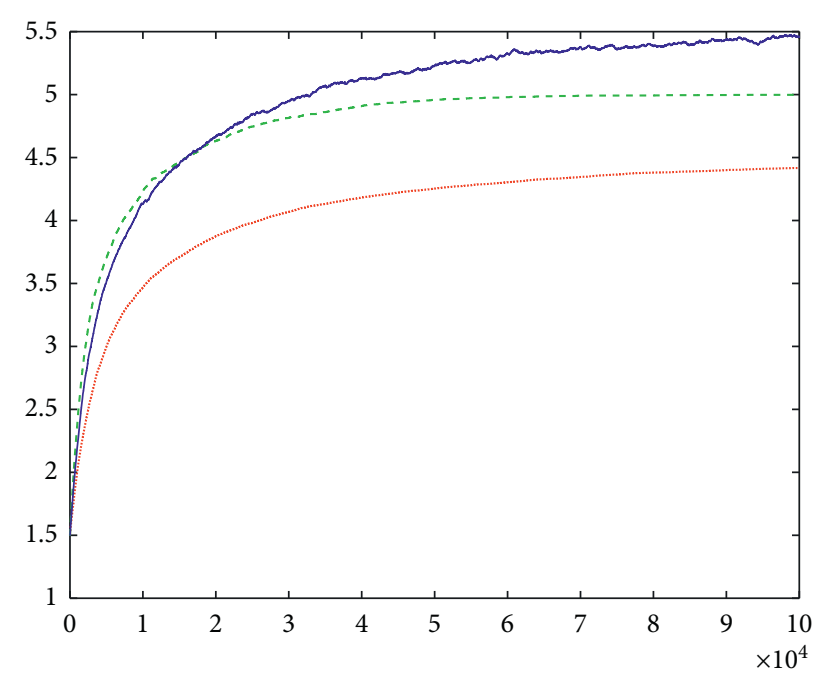

........ DP

-.. IP

- MP

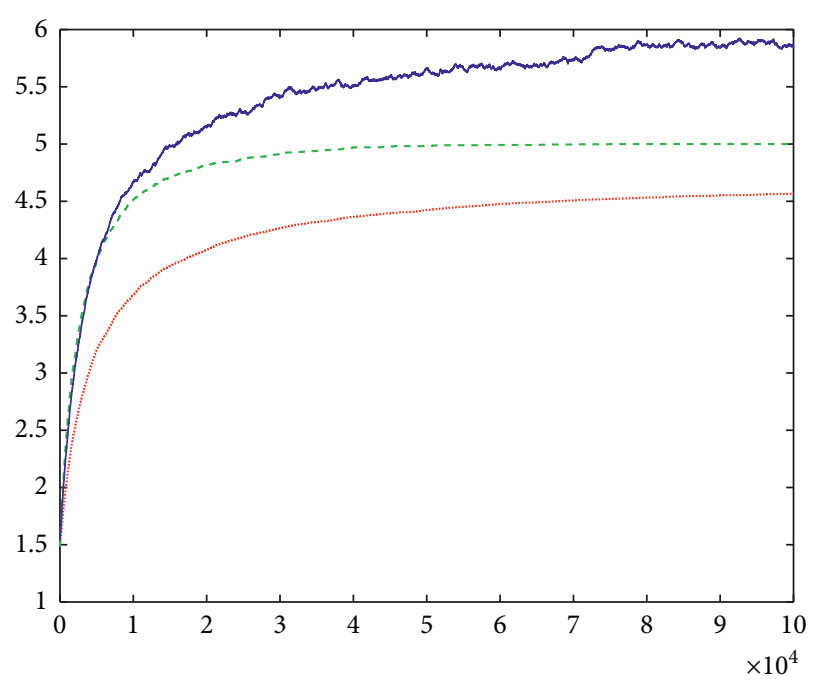

……. DP

-. - IP

- MP

Figure 6: Average knowledge levels in a scale-free network when $L=2,6$, and 8 .

influenced the effect of weak ties on knowledge equilibrium. This was because weak ties mainly reflect the understanding and acceptance degree of the innovation subject regarding the explicit knowledge diffused by other indirectly related subjects in the network. Therefore, with continuous increases in the number of weak ties, nodes were more likely to grasp the shared knowledge that was clearly encoded in the explicit knowledge-sharing channels, and the average knowledge level in the network reached its highest collaboration efficiency. Additionally, in a scale-free network, the network nodes often cooperated with the few nodes that had high cohesion, resulting in the relatively low aggregation of innovation nodes in the network and limited connection of the knowledge provider, which hindered the communication of implicit knowledge. 

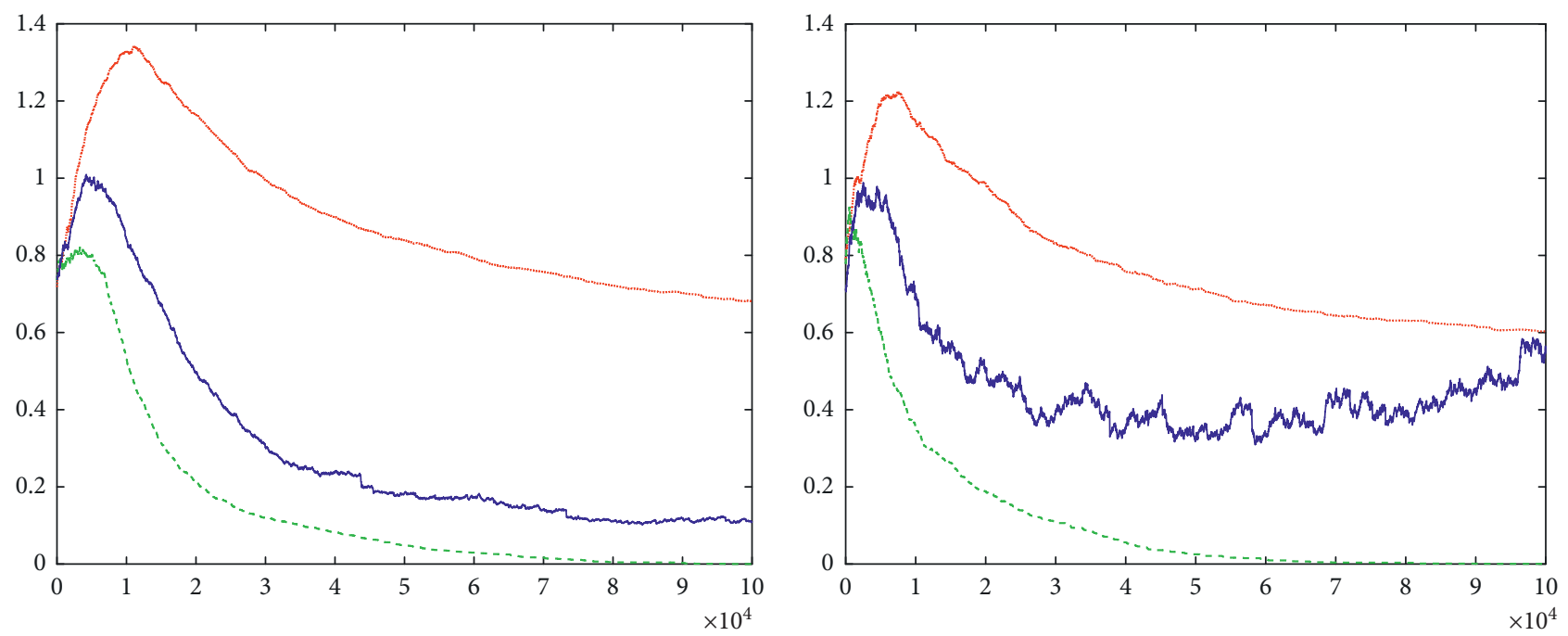

$$
\begin{array}{ll}
\ldots . . . . . . & \text { DP } \\
\ldots & \text { IP } \\
- & \text { MP }
\end{array}
$$$$
\text { ......... DP }
$$$$
\text { - . - IP }
$$$$
-\mathrm{MP}
$$

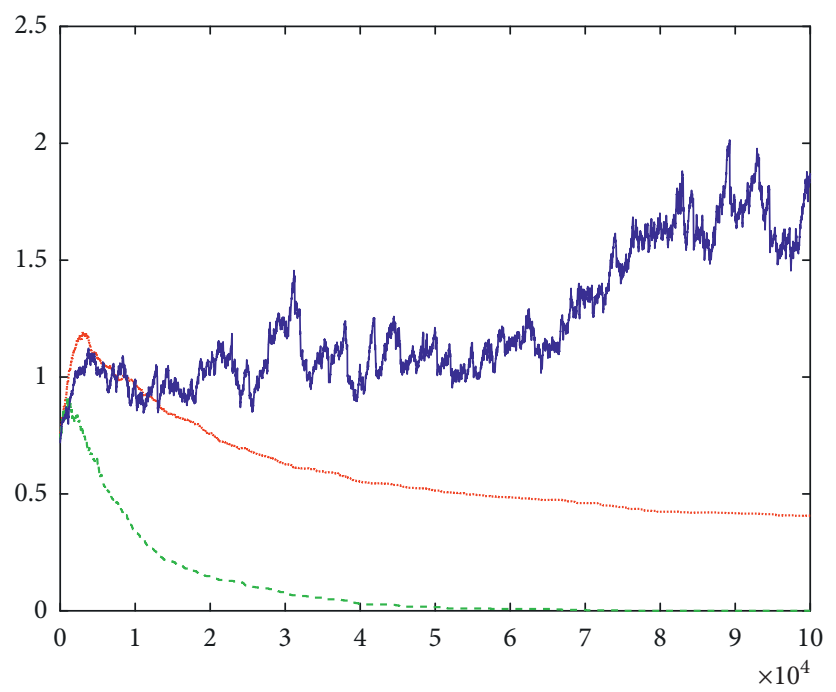

$$
\begin{array}{ll}
\text { …… DP } \\
\text {-- } \text { IP } \\
-\mathrm{MP}
\end{array}
$$

FIgUre 7: Knowledge equilibrium in a scale-free network when $L=2,6$, and 8 .

As shown in Figure 7, when examining the effect of weak ties on knowledge sharing in a scale-free network, we found that the average knowledge level in the network declined after a short-term rise. When the relationships between different nodes were relatively weak, IP encountered a block in knowledge transmission and relearning, and the knowledge sender and receiver did not share well, resulting in a decline in the equilibrium of network knowledge. After weak ties increased, knowledge equilibrium in MP gradually increased.

4.3. Knowledge Sharing in a Small-World Network. Figures 8-11 depict the effects of cohesion and the number of weak ties on knowledge sharing under DP, IP, and MP in the innovation network under a small-world topology. 

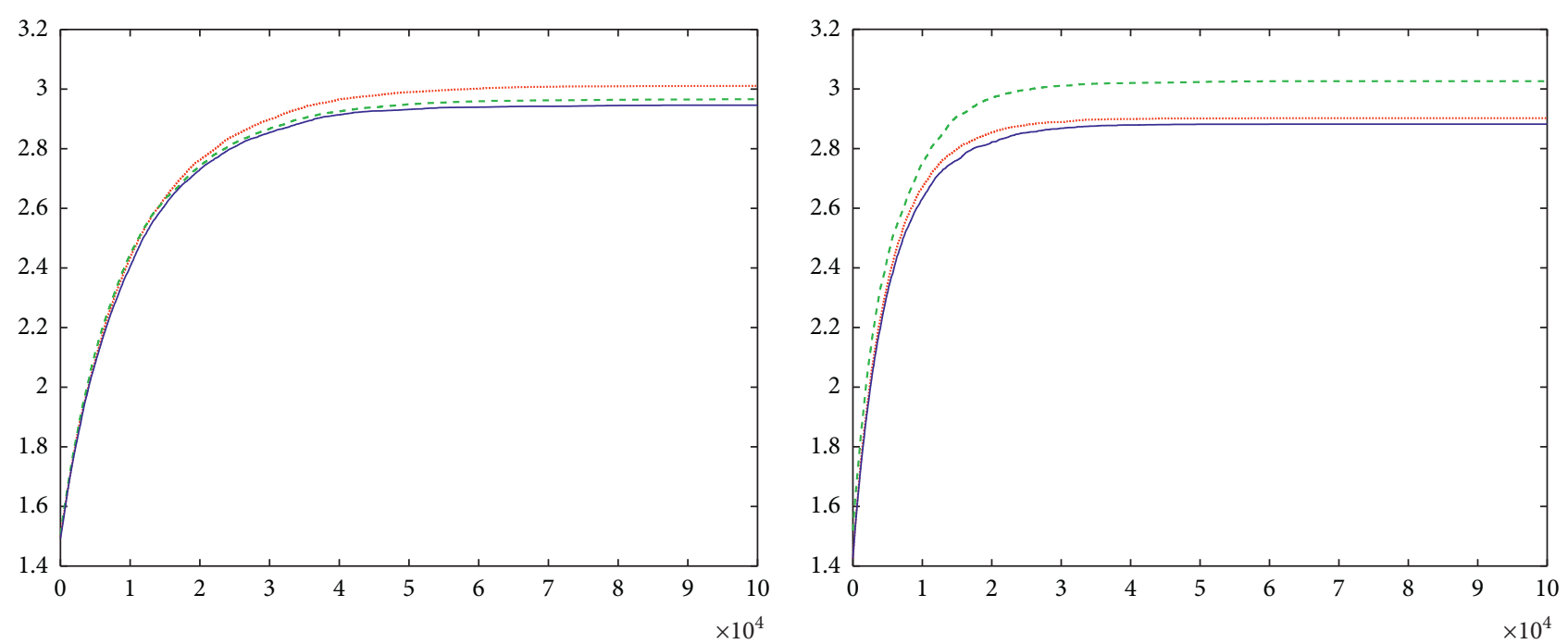

$\begin{array}{ll}\ldots . . . . . . . & \text { DP } \\ -\cdots & \text { IP } \\ - & \text { MP }\end{array}$

......... DP

-.. IP

$-\mathrm{MP}$

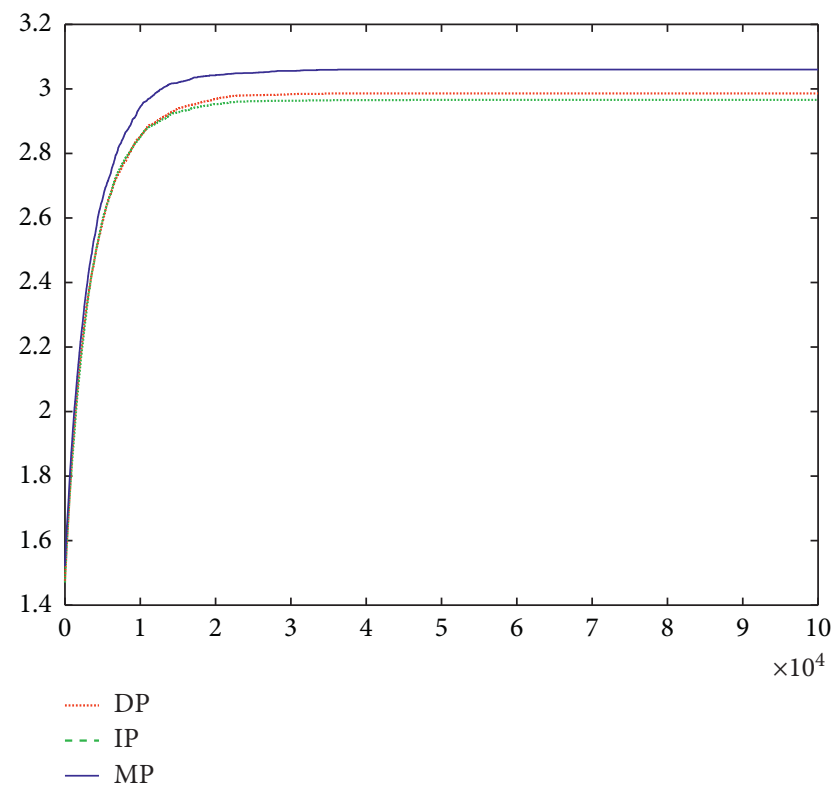

Figure 8: Average knowledge levels in a small-world network when $k=2$, 4, and 8 .

When node cohesion $k$ is 2 , 4 , and 8 , the average knowledge level and knowledge equilibrium in the innovation network under the small-world topology are shown in Figures 8 and 9.

Under the small-world topology, the average knowledge level in the innovation network reached the maximum under MP. The small-world network was more balanced, and the connections among partners in the network were distributed normally. The nodes in the innovation network were more evenly connected in the process of collaborative innovation, and they acquired implicit and explicit knowledge through balanced and comprehensive channels, causing innovation network knowledge to reach a higher level. The network nodes were 

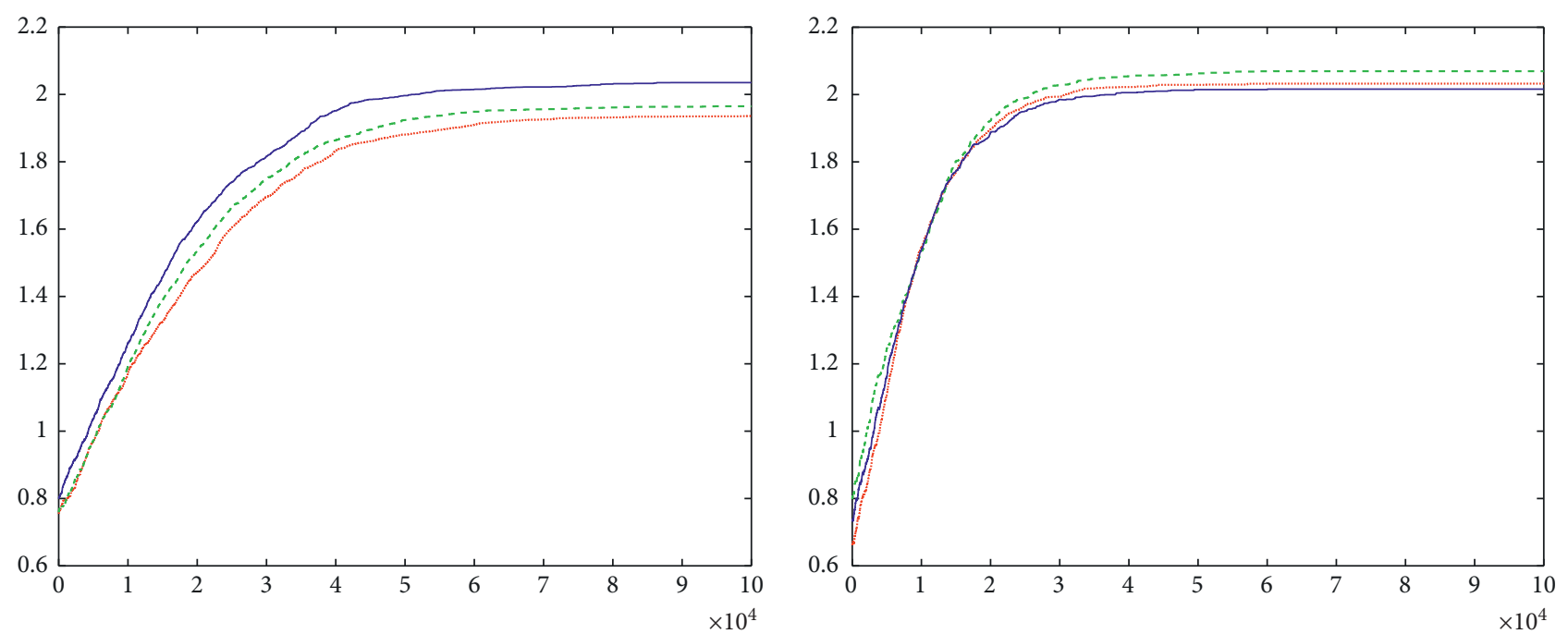

$\begin{array}{ll}\ldots . . . \cdots \cdot & \text { DP } \\ \text {-.- IP } \\ \text { - } \mathrm{MP}\end{array}$

DP
IP

- MP

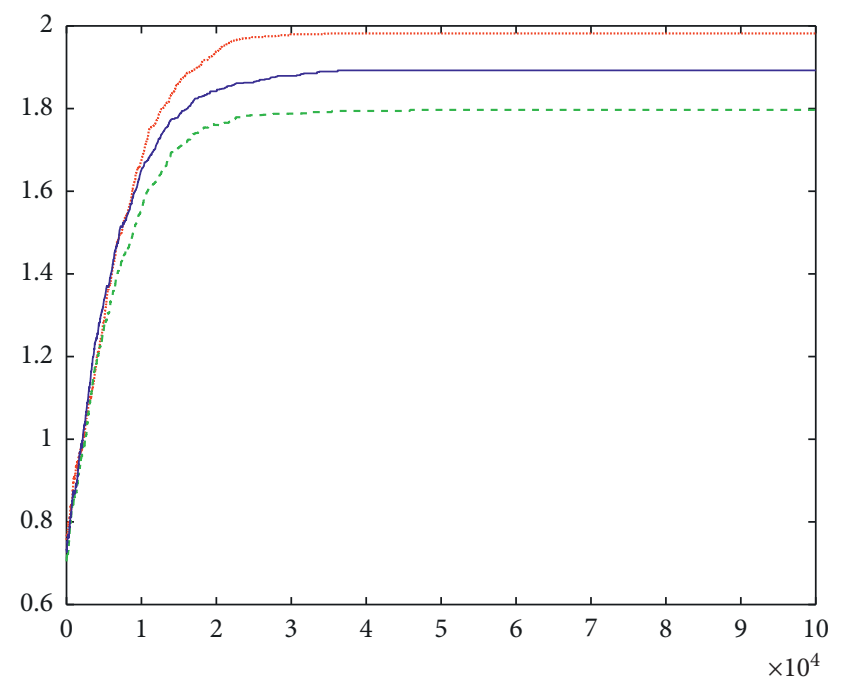

........ DP

- - - IP

- MP

FIGURE 9: Knowledge equilibrium in a small-world network when $k=2$, 4, and 8 .

less sensitive to node cohesion. In terms of knowledge equilibrium, DP had the greatest effect on knowledge variance. The small-world network exhibited close cooperation, and the nodes directly communicated with and trusted one another to obtain implicit knowledge. Therefore, the innovation network had the highest knowledge equilibrium under DP.
When the weak ties of node $L$ are 2,6 , and 8 , the average knowledge level and knowledge equilibrium in the innovation network are shown in Figures 10 and 11 under the small-world topology.

As shown in Figures 10 and 11, in an innovation network with small-world characteristics, MP played a significant role in promoting the average knowledge level 

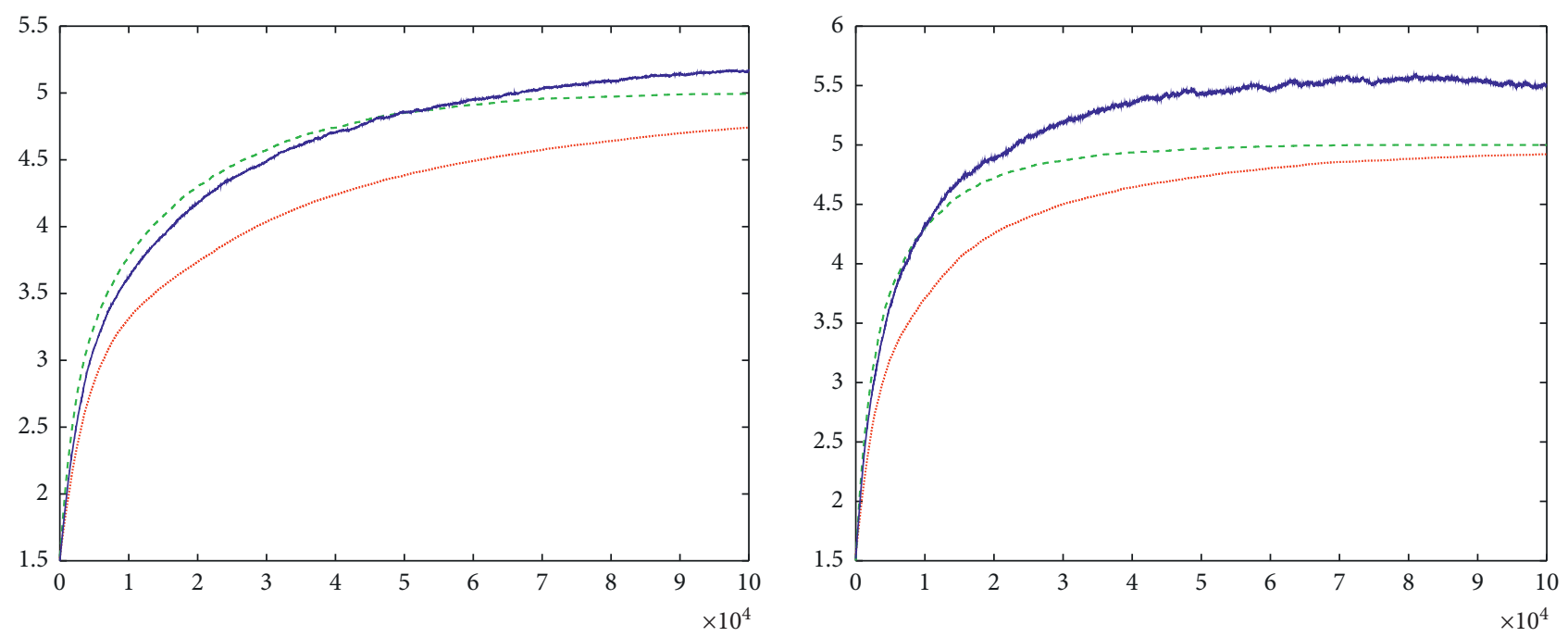

$\longrightarrow$ DP
$\ldots$ IP
$-\mathrm{MP}$
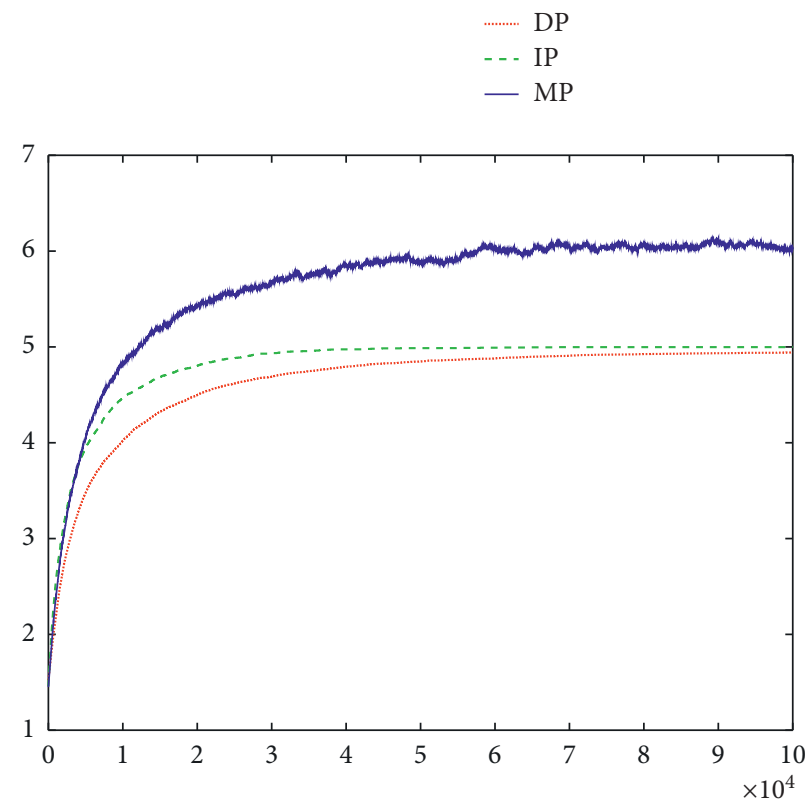

$\begin{array}{ll}\ldots . \cdots \cdots \cdots . . . & \text { DP } \\ --- & \text { IP } \\ - & \text { MP }\end{array}$

Figure 10: Average knowledge levels in a small-world network when $L=2$, 6 , and 8 .

and knowledge equilibrium in the network. In the smallworld network, the information dissemination path was short, the connection relationship between the innovation nodes was relatively close, and IP and DP both promoted the overall knowledge-sharing efficiency and level of the network. In addition, the efficiency and level of knowledge sharing were maximized when the two patterns coexisted.
Moreover, under MP, with an improvement in the learning level of the innovation subjects, knowledge variance fluctuated significantly. The small-world network was highly cohesive, and the network connection was relatively close. The richer the number of weak ties among the nodes, the more subjects they shared, causing knowledge equilibrium in the network to fluctuate. 

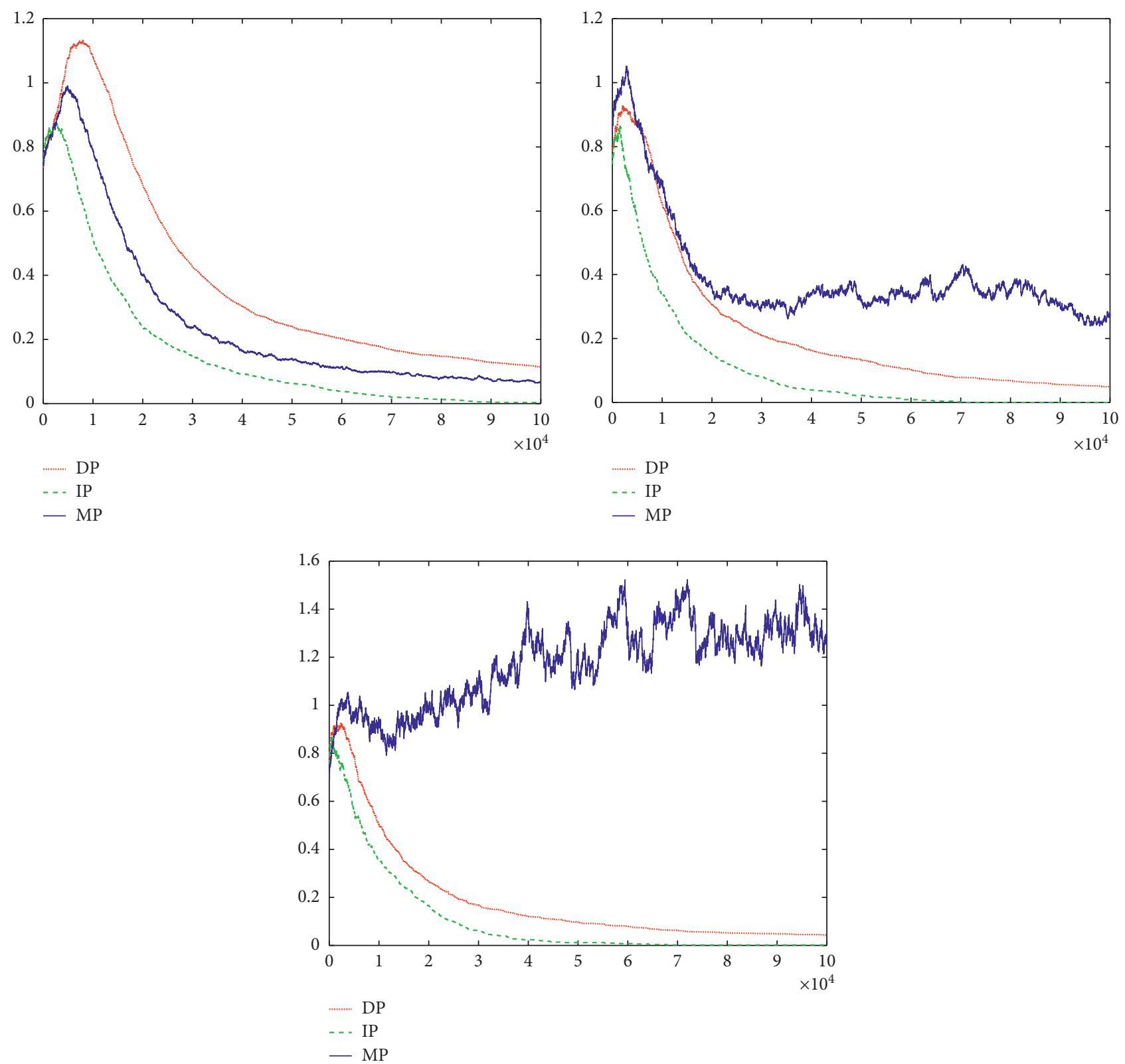

FIGURE 11: Knowledge equilibrium in a small-world network when $L=2,6$, and 8 .

\section{Conclusion}

Based on the model setting and simulation analysis, the following conclusions can be drawn.

First, innovation network structures had different effects on knowledge sharing with different paths. Furthermore, node cohesion and the number of weak ties for making knowledge more explicitly affected the network's level of knowledge sharing.

Second, in the innovation network with a scale-free topology, node cohesion and the number of weak ties for making knowledge more explicitly significantly influenced the average knowledge level and knowledge equilibrium of the network. Overall, the direct path and mixed path had stronger effects on promoting knowledge sharing in the innovation network.
Third, in the innovation network with a small-world topology, the mixed path had the best effect on promoting the network's overall knowledge level.

Based on these findings, this study can provide a reference for improving knowledge sharing in the context of innovation networks.

Most importantly, we need to build harmonious and innovative networks. Since an innovation network includes many innovation subjects, and different subjects have different corporate concepts and cultures, innovation subjects express different opinions during collaboration and cooperation. Most enterprises lack a culture of cooperation for achieving win-win situations, which results in excessive competition in the innovation network, wasted innovation resources, and reduced efficiency. Therefore, at this stage of collaborative innovation, a corporate concept is needed to cultivate an appropriate concept 
of collaborative innovation and achieve the goal of mutual benefit under the joint efforts of both parties. In addition, the simulation analysis showed that a small-world topology was more conducive to knowledge collaboration and innovation in an innovation network. The most prominent feature of the small-world network was that the average network path length was short, and cohesion was strong. Therefore, trust among various innovation subjects should be cultivated to create a sound atmosphere for cooperation. Subjects who demonstrate opportunistic behavior and bring invisible losses to innovation activities should be sanctioned. Only by maintaining the trust relationship between organizations can we communicate and learn better.

This study does have some limitations. Specifically, simulation was used to estimate the trends of knowledge diffusion in multinetworks. Though the parameter settings were based on consultation with experts in the field, future research could perhaps use real numerical values. In addition, this study only considers the influence of some network characteristics on knowledge sharing, other characteristics (such as clustering coefficient) may research in the future.

\section{Data Availability}

The data used to support the findings of this study are available from the corresponding author upon request.

\section{Conflicts of Interest}

The authors declare that they have no conflicts of interest.

\section{Acknowledgments}

This research was supported by the Ministry of Education of China's Project of Humanities and Social Sciences (Grant no. 18YJC630245), the National Natural Science Foundation of China (Grant no. 71804084), and the National Social Science Fund Project (Grant no. 17CZZ005). The authors also wish to thank Prof. Yi Su and Dr. Shili Wang for the simulation and for providing useful suggestions.

\section{References}

[1] B. V. Looy, K. Debackere, J. Callaert et al., "Scientific capabilities and technological performance of national innovation systems: an exploration of emerging industrial relevant research domains," Scientometrics, vol. 66, no. 2, pp. 295-310, 2006.

[2] H. Liu, Y. Yang, and Y. Han, "Research on periodic evolution characteristics and policy dynamic adjustment mechanism of strategic emerging industry: a literature review," Science and Technology Management Research, vol. 38, no. 7, pp. 142-147, 2018.

[3] J. Jiang, Y. Zhang, and X. Wang, "Progress and future agenda for the technological innovation network in the view of knowledge evolution," Science Research Management, vol. 30, no. 3, pp. $68-133,2010$.

[4] L. Li, J. Xie, R. Wang, J. Su, and S. Sindakis, "The partner selection modes for knowledge-based innovation networks: a multiagent simulation," IEEE Access, vol. 7, pp. 140969140979, 2019.
[5] R. Cowan, N. Jonard, and J.-B. Zimmermann, "Bilateral collaboration and the emergence of innovation networks," Management Science, vol. 53, no. 7, pp. 1051-1067, 2007.

[6] S. Davenport, A. Carr, and D. Bibby, "Leveraging talent: spin-off strategy at industrial research," RङD Management, vol. 32, no. 3, pp. 241-254, 2010.

[7] Ja De Ridder, "Organisational communication and supportive employees," Human Resource Management Journal, vol. 14, no. 3, pp. 20-30, 2010.

[8] S. Ilwon and W. S. Jung, "The persistence of inter-regional hierarchy in technology transfer networks: an analysis of Chinese patent licensing data," Growth and Change, vol. 50, no. 1, pp. 145-163, 2019.

[9] Senge and C. Jeffrey, "How technology has improved my access to information," Technology and Disability, vol. 6, no. 3, pp. 191-198, 1997.

[10] H. Paul, "Why share knowledge? the influence of ICT on the motivation for knowledge sharing," Knowledge \& Process Management, vol. 6, no. 2, pp. 91-100, 2015.

[11] G. W. Bock, R. W. Zmud, Y. G. Kim, and fnm Lee, "Behavioral intention formation in knowledge sharing: examining the roles of extrinsic motivators, social-psychological forces, and organizational climate," MIS Quarterly, vol. 29, no. 1, pp. 87-111, 2005.

[12] S. Ravindran and G. S. Iyer, "Organizational and knowledge management related antecedents of knowledge use: the moderating effect of ambiguity tolerance," Information Technology and Management, vol. 15, no. 4, pp. 271-290, 2014.

[13] M. T. Hansen and T. Morten, "Knowledge networks: explaining effective knowledge sharing in multiunit companies," Organization Science, vol. 13, no. 3, pp. 232-248, 2002.

[14] J. N. Cummings, "Work groups, structural diversity, and knowledge sharing in a global organization," Management Science, vol. 50, no. 3, pp. 352-364, 2004.

[15] R. S. Burt and S. Ronald, "Structural holes and good ideas," American Journal of Sociology, vol. 110, no. 2, pp. 349-399, 2004.

[16] E. Liu and Q. Chen, "Incentive mechanism and countermeasures research on knowledge sharing among knowledge alliance members," International Conference on Management \& Service Science, vol. 14 pages, 2011.

[17] Watts and J. Duncan, "Networks, dynamics, and the smallworld phenomenon," American Journal of Sociology, vol. 105, no. 2, 10 pages, 1999.

[18] R. Cowan and N. Jonard, "Network structure and the diffusion of knowledge," Journal of Economic Dynamics and Control, vol. 28, no. 8, pp. 1557-1575, 2004.

[19] and Lin Xu, "Identifying peer effects in student academic achievement by a spatial autoregressive model with group unobservable," Journal of Labor Economics, vol. 28, pp. 825860, 2010.

[20] Y. Su and T. C. Li, "Simulation analysis of knowledge transfer in a knowledge alliance based on a circular surface radiator model," Complexity, vol. 2020, Article ID 4301489, 27 pages, 2020.

[21] K. Sweeney, "Personal knowledge," BMJ-British medical journal, vol. 332, no. 7534, pp. 129-130, 2006.

[22] I. Nonaka and H. Takeuchi, "The knowledge-creating company: how Japanese companies create the dynamics of innovation," Journal of International Business Studies, vol. 27, no. 1, pp. 196-201, 1996.

[23] T. Haldin Herrgard, "Difficulties in diffusion of tacit knowledge in organizations," Journal of Intellectual Capital, vol. 1, no. 4, pp. 357-365, 2000. 
[24] M. Usman, M. I. Ahmad, and J. Burgoyne, "Individual and organizational learning from inter-firm knowledge sharing: a framework integrating inter-firm and intra-firm knowledge sharing and learning," Canadian Journal of Administrative Sciences/Revue Canadienne des Sciences de l'Administration, vol. 36, no. 4, pp. 484-497, 2019.

[25] T. H. Davenport and P. Klahr, "Managing customer support knowledge," California Management Review, vol. 40, no. 3, pp. 195-208, 1998.

[26] V. Krogh, "Care in knowledge creation," California Management Review, vol. 40, no. 3, pp. 133-153, 1998.

[27] Z. Ba, G. Li, and S. Zhu S, "Knowledge diffusion mechanism of scientific cooperation network," Journal of Library Science in China, vol. 42, no. 5, pp. 68-84, 2016.

[28] A. Pässilä, T. Uotila, and H. Melkas, "Facilitating futureoriented collaborative knowledge creation by using artistic organizational innovation methods: experiences from a finnish wood-processing company," Futures, vol. 47, no. 3, pp. 59-68, 2013.

[29] M. F. Peschl and T. Fundneider, "Designing and enabling spaces for collaborative knowledge creation and innovation: from managing to enabling innovation as socio-epistemological technology," Computers in Human Behavior, vol. 37, no. 8, pp. 346-359, 2014.

[30] L. Koch and M. Simmler, "How important are local knowledge spillovers of public R\&D and what drives them," Research Policy, vol. 49, no. 7, pp. 1-14, 2020.

[31] N. L. Klenk and S. Wyatt, "The design and management of multi-stakeholder research networks to maximize knowledge mobilization and innovation opportunities in the forest sector," Forest Policy and Economics, vol. 61, pp. 77-86, 2015.

[32] C. I. Andrew and D. Adva, "Knowledge management processes and international joint ventures," Organization Science, vol. 9, no. 4, pp. 454-468, 1998.

[33] U. Andersson, M. Forsgren, and U. Holm, "Balancing subsidiary influence in the federative MNC: a business network view," Journal of International Business Studies, vol. 38, no. 5, pp. 802-818, 2007.

[34] P. W. Anderson, "More is different," Science, vol. 177, no. 4047, pp. 393-396, 1972.

[35] J.-P. Wang, Q. Guo, G.-Y. Yang, and J.-G. Liu, "Improved knowledge diffusion model based on the collaboration hypernetwork," Physica A: Statistical Mechanics and Its Applications, vol. 428, pp. 250-256, 2015.

[36] I. Hiroyasu, "A two-layer team-assembly model for invention networks,” Physica A, vol. 415, pp. 181-188, 2014.

[37] S. Luo, Y. Du, P. Liu, Z. Xuan, and Y. Wang, "A study on coevolutionary dynamics of knowledge diffusion and social network structure," Expert Systems With Applications, vol. 42, no. 7, pp. 3619-3633, 2015.

[38] L. Fleming and K. Frenken, "The evolution of inventor networks in the silicon valley and boston regions," Advances in Complex Systems, vol. 10, no. 01, pp. 53-71, 2007.

[39] A. Ebadi and A. Schiffaueroval, "On the relation between the small world structure and scientific activities," Plos One, vol. 10, no. 3, pp. 1-19, 2015.

[40] X. Cao and L. Zhang, "Research on the evolution of innovation network's cooperation density based on the benefit distribution," Journal of Systems Engineering, vol. 31, no. 1, pp. 1-12, 2013.

[41] L. Zhang, L. Xue, and Y. Zhou, "How do low-carbon policies promote green diffusion among alliance-based firms in China? an evolutionary-game model of complex networks," Journal of Cleaner Production, vol. 210, pp. 518-529, 2019.
[42] J. Leskovec, D. Chakrabarti, J. Kleinberg et al., "Kronecker graphs: an approach to modeling networks," Machine Learning Research, vol. 11, pp. 985-1042, 2010.

[43] J. F. Benjamin, S. Wuchty, and B. Uzzi, "Multi-university research teams: shifting impact, geography, and stratification in science," Science, vol. 322, no. 5905, pp. 1259-1262, 2008.

[44] W. Tsai, "Knowledge transfer in intraorganizational networks: effects of network position and absorptive capacity on business unit innovation and performance," Academy of Management Journal, vol. 44, no. 5, pp. 996-1004, 2001.

[45] F. Zand, S. Solaimani, and C. van Beers, "A role-based typology of information technology: model development and assessment," Information Systems Management, vol. 32, no. 2, pp. 119-135, 2015.

[46] L. Hossain and A. de Silva, "Exploring user acceptance of technology using social networks," The Journal of High Technology Management Research, vol. 20, no. 1, pp. 1-18, 2009.

[47] B. Batjargal, M. A. Hitt, A. S. Tsui, J.-L. Arregle, J. W. Webb, and T. L. Miller, "Institutional polycentrism, entrepreneurs' social networks, and new venture growth," Academy of Management Journal, vol. 56, no. 4, pp. 1024-1049, 2013.

[48] H. Graf, "Gatekeepers in regional networks of innovators," Jena Economic Research Papers, vol. 54, pp. 173-198, 2007.

[49] G. Cepeda and D. Vera, "Dynamic capabilities and operational capabilities: a knowledge management perspective," Journal of Business Research, vol. 60, no. 5, pp. 426-437, 2007.

[50] Y. Xi and Y. Dang, "A method to represent and measure personal knowledge stocks based on weighted knowledge network," Chinese Journal of Management, vol. 4, no. 1, pp. 28-171, 2007.

[51] D. J. Watts and S. H. Strogatz, "Collective dynamics of "smallworld” networks," Nature, vol. 393, no. 6684, pp. 440-442, 1988.

[52] Barabá and A. Si, "Emergence of scaling in random networks," Science, vol. 286, no. 5439, pp. 509-512, 1999.

[53] S. Wang and Y. Sheng, "Cluster innovation network cooperation degree, network openness, and cluster incremental performance with the environmental uncertainty," Science Research Management, vol. 32, no. 2, pp. 52-61, 2013.

[54] I. Nonaka, "The knowledge-creating company," Harvard Business Review, vol. 69, no. 6, pp. 96-104, 1991.

[55] P. S. Dodds, R. Muhamad, and D. Watts, "An experimental study of search in global social networks," Science, vol. 301, no. 5634, pp. 827-829, 2003. 